\section{Urologia \\ Internationalis}

\title{
Imaging in Prostate Cancer Diagnosis: Present Role and Future Perspectives
}

\author{
Francesco Pinto \\ Angelo Totaro \\ Alessandro Calarco \\ Emilio Sacco \\ Andrea Volpe \\ Marco Racioppi \\ Alessandro D'Addessi \\ Gaetano Gulino \\ PierFrancesco Bassi
}

Department of Urology, Catholic

University of Sacred Heart, Rome, Italy

\section{Key Words}

Prostate cancer $\cdot$ Magnetic resonance imaging .

Diffusion-weighted MRI • Dynamic contrast-enhanced MRI •

MR spectroscopy · Prostate ultrasonography imaging •

Prostate biopsy

\section{Abstract}

Prostate cancer ( $\mathrm{PCa}$ ) remains a major health concern for the male population. Detection and primary diagnosis of $\mathrm{PCa}$ are based on digital rectal examination, serum prostate-specific antigen levels, and transrectal ultrasound (TRUS)-guided random biopsy. Moreover, the gold standard for detecting PCa, systematic biopsy, lacks sensitivity as well as grading accuracy. This review summarizes recent developments of ultrasonography modalities and functional magnetic resonance imaging (MRI) in the diagnosis of $\mathrm{PCa}$. A comparison between the different methods is presented, including their clinical value and usefulness. It is concluded that innovative ultrasound techniques (including ultrasound contrast agents, 3-D and 4-D sonography, elastography and harmonic sonography) promise benefits in comparison to standard TRUS to accurately diagnose PCa. Promising advances have been made in the detection of PCa with multiparametric MRI. The combination of conventional and functional MRI techniques (including diffusion-weighted imaging, dynamic contrast-enhanced MRI, and MR spectroscopy) can provide information for differentiating PCa from noncancerous tis- sue and can be used for MRI-guided biopsies, especially in patients with persistent elevation of serum prostate-specific antigen and previous negative TRUS-guided biopsies. However, functional MRI technique and MRI-guided biopsy remain expensive and complex tools presenting inherent challenges.

Copyright $\odot 2011$ S. Karger AG, Basel

\section{Introduction}

Prostate cancer $(\mathrm{PCa})$ is the most common cancer in men in Europe [1]. Among men in the EU, PCa accounts for approximately $11.9 \%$ of all cancers and $9 \%$ of all cancer deaths [1]. Despite advances in PCa detection and treatment, the disease continues to represent an enormous healthcare burden. Early PCa detection is the main topic of diagnostic imaging and the key to successful cancer treatment [2]. To date, the suspicion of $\mathrm{PCa}$ is mainly based on three diagnostic tools: serum prostate-specific antigen (PSA), digital rectal examination (DRE) and transrectal ultrasound (TRUS) of the prostate, each of them presenting well-known limitations [2, 3]. Nowadays, random TRUS-guided biopsy is the gold standard method for histological diagnosis of PCa [4]. However, random biopsies have several disadvantages: (a) missing cancer in up to $35 \%$ of cases [4]; (b) presence of multiple foci in more than $85 \%$ of cases of PCa [5]; (c) increase in

\section{KARGER \\ Fax +4161306 1234 E-Mail karger@karger.ch} www.karger.com

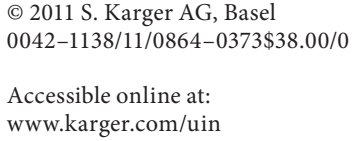

Francesco Pinto

Department of Urology, Catholic University of Sacred Heart

Largo A. Gemelli

IT-00168 Rome (Italy)

Tel. +39 063015 5290, E-Mail francesco.pinto @libero.it 
complications because of unnecessary biopsies. Moreover, men with persistently elevated PSA levels after a negative first random TRUS-guided biopsy represent a great diagnostic challenge for urologists [6]. For these reasons, new imaging techniques are necessary to allow $\mathrm{PCa}$ visualization in order to improve cancer detection rate. To date, no consensus exists regarding the use of imaging techniques for evaluating primary PCas. Current standard imaging techniques, such as ultrasound, magnetic resonance imaging (MRI), CT, and nuclear medicine, cannot detect early disease, and they provide limited information for disease staging [7]. However, several promising emerging techniques are under investigation, either alone or in conjunction with standard imaging techniques. Evolving methods such as 3-D/4-D TRUS, contrast-enhanced ultrasound techniques, elastography and multiparametric MRI such as dynamic contrast material-enhanced MRI (DCE-MRI), diffusion-weighted imaging (DWI), and MR spectroscopy imaging may dramatically change the role of imaging for PCa diagnosis [8-13]. The aim of this article is to review the current clinical status of advanced imaging techniques and future perspectives for the detection of PCa.

\section{Evidence Acquisition}

The authors searched the Medline, Embase, and Cochrane Library databases. Only studies in English were evaluated. The last search was performed in June 2010.

\section{Sonography Imaging}

\section{Transrectal Ultrasonography}

TRUS provides real-time imaging of the prostate gland at a relatively low cost. However, it suffers from lack of specificity, especially if the investigator is still fairly inexperienced [14]. To improve PCa detection, various biopsy strategies have been devised to increase the diagnostic yield of prostate biopsy: sampling of visually abnormal areas, more lateral placement of biopsies, anterior biopsies, and obtaining an increased number of cores, with up to 45 biopsy cores [15-18]. On the one hand, the efficiency of this practice is debated and limited in practice by patient tolerance and morbidity. On the other hand, several studies have shown that systematic biopsy still misses a considerable number of PCa $[19,20]$. On gray-scale evaluation, $\mathrm{PCa}$ are classically described as a hypoechoic lesion; however, they may be isoechoic or hyperechoic [14]. Many PCa are not visible on standard ultrasound, and the predictive value of hypoechoic lesion is $25-30 \%$
[17]. Therefore, new strategies for PCa detection have been investigated to improve the quality of the investigation instead of raising the quantity of biopsies, and thus to reduce the number of unnecessary 'blind' biopsies.

\section{Innovative Sonography Techniques}

$3-D / 4-D$ Sonography. It is essential when performing prostate ultrasound to carefully evaluate the entire gland for different types of lesions and to perform biopsies on subtle as well as obvious lesions, in addition to performing random biopsies to identify 'invisible' cancers. Gray-scale 2-D TRUS has relatively poor ability to detect palpable and nonpalpable cancers and predict disease outcome [20]. 3-D ultrasound has become mainstream in gynecologic and obstetric application, but the use in urologic application is relatively limited. 3-D ultrasound allows simultaneous biplanar imaging of the prostate with computer reconstructions providing a coronal plane as well as a rendered 3-D image. 3-D ultrasound of prostate improves the diagnostic accuracy for exact localization of only hypoechoic areas, particularly on the coronal view [21]. Moreover, a recent study of Abul et al. [22] showed an improvement in diagnostic accuracy of PCa for 4-D TRUS. Nevertheless, there is still a group of patients with 'invisible' cancers. Therefore, the policy of random biopsies has to be continued until this incidence can be eliminated.

Contrast-Enhanced Sonography. Using intravenous microbubble agents in combination with color and power Doppler imaging modalities, an increase in signal is obtained in areas of increased vascularity. In a study conducted by Pelzer et al. [23] on 380 patients with suspected PCa (PSA level between 4 and $10 \mathrm{ng} / \mathrm{ml}$ ), contrastenhanced color Doppler-targeted biopsies (five cores) in areas of hypervascularity were compared with standard biopsies (10 cores). Based on cancer detected by biopsy, the detection rate of targeted biopsy cores was significantly better than standard biopsy cores (32.6 vs. $17.9 \%$, $\mathrm{p}<0.01)$ [23]. Similar results were found in another study conducted by Halpern [24] on 301 patients, in which targeted biopsy was 1.5 times more likely to find tumor than was systematic biopsy ( 15.5 vs. $10.4 \%, \mathrm{p}<0.01)$. Nevertheless, targeted biopsies missed $20 \%$ of cancers, which were detected on systematic biopsy alone, leading to the conclusion that systematic biopsy could not be omitted from a biopsy scheme [24]. The study by Yi et al. [25] demonstrated that the sensitivity on biopsy site was greater on contrast-enhanced sonography (68\%) than on gray-scale (39\%) and color Doppler (41\%) sonography. Moreover, Drudi et al. [26] demonstrated that contrastenhanced sonography may also be used in the diagnosis 
of local recurrence after radical prostatectomy in patients with increasing PSA.

Harmonic Sonography. Intermittent imaging is an ultrasound technique that employs a reduced frame rate, allows more time for the contrast agent to enter the scan plane between frames, and thereby increases the intensity of microbubble contrast enhancement $[27,28]$. Preliminary data suggest that intermittent gray-scale harmonic imaging (IHI) can increase the conspicuity of microvascular enhancement associated with PCa [29]. Moreover, in the study conducted by Halpern [24], it has been demonstrated that contrast-enhanced transrectal sonography with IHI provides a statistically significant improvement in discrimination between benign and malignant biopsy site, and the carcinoma detection rate of contrast-enhanced targeted cores is significantly higher when compared with sextant cores. However, given the relatively low ROC areas $(<0.65)$, this technique did not definitively differentiate benign from malignant tissue without biopsy confirmation.

Elastography. Elastography is an imaging technique that evaluates the elasticity of the tissue. Prostate carcinomas are characterized by a partly limited elasticity or compressibility. Miyanaga et al. [30] investigated 29 patients with untreated PCa. The sensitivity of elastography, TRUS and DRE was 93, 59 and 55\%, respectively [30]. Thus, elastography may be used as biopsy guidance in the diagnosis of PCa. In a pilot study on 404 patients, König et al. [31] have demonstrated an improved PCa detection rate $(20 \%)$ when combining this method with conventional TRUS during prostate biopsies. In a recent study on 492 patients, Pallwein et al. [32] showed that elastography-targeted biopsy in a patient with cancer was 2.9 -fold more likely to detect PCa than systematic biopsy, with fewer than half the number of biopsy core. Although the results with elastography had shown some promising results, its role in PCa diagnosis needs to be evaluated further.

\section{Pre-Biopsy MRI and Real-Time TRUS: Near Future}

In a recent study, Singh et al. [33] described the feasibility of fusioning pre-biopsy MRI data with real-time TRUS imaging using fiducial markers. In another study, Xu et al. [34] proposed a hybrid registration approach for real-time MRI/TRUS image fusion, bringing the diagnostic information from the MRI to ultrasound procedures. The approach is based on both spatial tracking and intraoperative image registration, which allows compensation for prostate motion without the use of fiducial markers. That way, it is likely that in the near future, can-

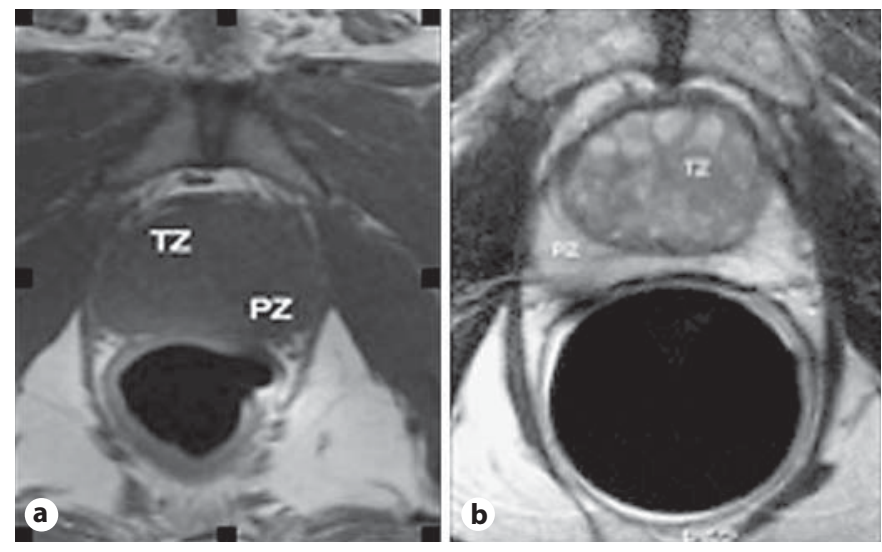

Fig. 1. Normal prostate gland, endorectal MRI, axial image. a $\mathrm{T}_{1}$-WI: prostate shows a uniform intermediate signal intensity. b $\mathrm{T}_{2}$-WI: prostate shows a high signal intensity of the peripheral and low signal intensity of the central and transitional zones. $\mathrm{PZ}=$ Peripheral zone; $\mathrm{TZ}=$ transitional zone.

cers could be identified at MRI, contoured, transferred to the ultrasound device and superimposed on real-time ultrasound imaging to improve their aiming of targeted biopsies and facilitate potential MRI-guided prostate therapies such as external beam radiation therapy, brachytherapy, cryotherapy, HIFU ablation, or direct injection of agents [35]. In this way, multi-modality imaging with electromagnetic tracking of enabled devices can draw from the benefits of one method, while avoiding the limitations of another. For example, this perspective is especially interesting for anterior cancers that can be detected at pre-biopsy MRI but lie in a 'gray zone' of the TRUS biopsies (18-20 $\mathrm{mm}$ beyond the capsule) and additionally cannot be targeted using standard ultrasound imaging.

\section{Magnetic Resonance Imaging}

Conventional MRI at 1.5 or $3.0 \mathrm{~T}$ reveals morphological information using $\mathrm{T}_{1^{-}}$and $\mathrm{T}_{2}$-weighted images $\left(\mathrm{T}_{1^{-}}\right.$ and $\mathrm{T}_{2}$-WI), and the usage of an endorectal coil can improve the detection of $\mathrm{PCa}$ and the delineation of the capsule [36] (fig. 1, 2). The value of 3.0-tesla MRI of the prostate is recently under research and seems to be promising $[36,37] . \mathrm{T}_{2}$-WI provides high-resolution morphologic imaging of the gland in the three planes, and axial $\mathrm{T}_{1}$-WI is used to detect post-biopsy hemorrhage, lymph nodes, and bone metastasis. On $\mathrm{T}_{2}-\mathrm{WI}$, peripheral zone cancer typically shows a uniformly low signal with a nod- 


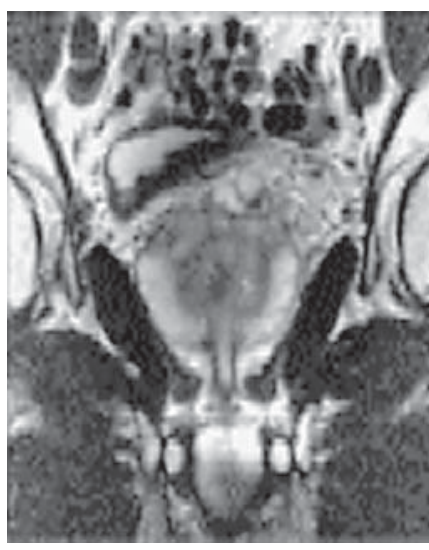

Fig. 2. Normal prostate gland, endorectal MRI, coronal image.

ular shape within the peripheral zone that shows high signal intensity [38] (fig. 3). However, there are numerous false positives because low intense signal in peripheral zone can also be caused by inflammation, hemorrhage, sequelae of radiation and hormonal treatment, etc. For this reason, MRI should be delayed for at least 4-8 weeks after prostate biopsy $[39,40]$. In the transitional zone, cancer detection on $\mathrm{T}_{2}-\mathrm{WI}$ is hampered by benign hyperplasic nodules that have highly variable signal (from high-intensity cysts to very-low-intensity stromal nodules) and a nodular appearance. Thus, the sensitivity and specificity of $\mathrm{T}_{2}$-weighted MR imaging for PCa detection have varied widely. Sensitivity of $77-91 \%$ and specificity of $27-61 \%$ were reported for PCa detection with $\mathrm{T}_{2}$ weighted imaging performed with an endorectal coil [41, 42]. In the last two decades, intense research has focused on complementary techniques to improve the detection and staging of PCa. In a recent review on multiparametric MRI in PCa, Kurhanewicz et al. [43] concluded that the best characterization of PCa in individual patients will most likely result from multiparametric MRI techniques based on anatomic, metabolic and physiologic properties of $\mathrm{PCa}$, using 3-tesla magnetic resonance scanners. However, questions remain as how to analyze and display this large amount of imaging data, and how to optimally combine the data for the most accurate assessment of PCa. Cancer identification at MRI requires a combination of morphologic $\mathrm{T}_{2}$-WI and functional imaging (perfusion, diffusion, and spectroscopy). Currently used functional MRI techniques include: magnetic resonance spectroscopic imaging (MRSI), dynamic contrastenhanced MRI, and DWI-MRI. A magnet strength of at
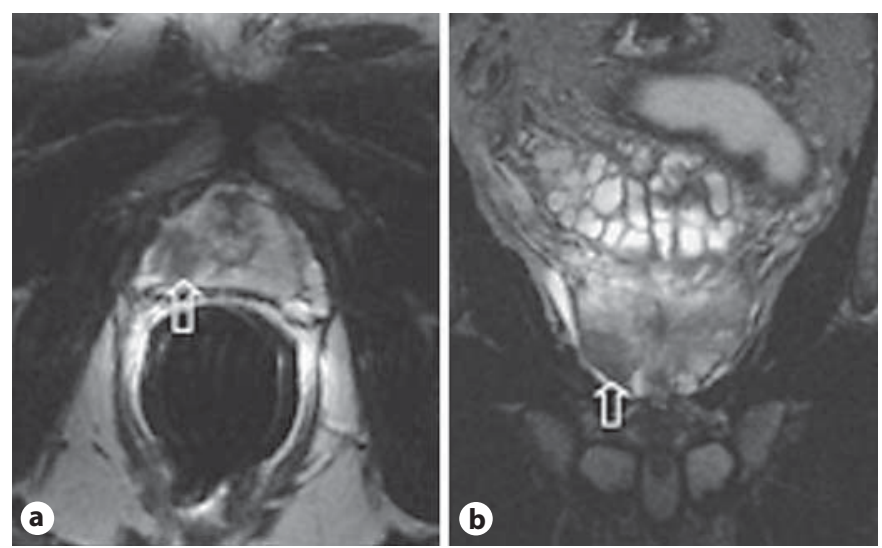

Fig. 3. $\mathrm{T}_{2}$-weighted axial (a) and coronal (b) images with endorectal coil show an area of low signal intensity (arrow) in the right peripheral zone of the prostate, a finding indicative of a tumor.

least $1.5 \mathrm{~T}$ is required for a simultaneous use of MRI and MRSI in order to overlay metabolic information directly on the corresponding anatomic display $[44,45]$.

\section{Magnetic Resonance Spectroscopic Imaging}

MRSI allows assessment of tissue metabolism in a single or multiple voxels. The metabolites measured by in vivo MRSI are citrate, creatine, choline and polyamines [46]. Typically, PCa shows a high level of choline and a low level of citrate relative to the normal peripheral zone with a high specificity but at the expense of sensitivity [46-48] (fig. 4).

In the last decade, many publications have studied the advantages of the combined use of MRI and MRSI in order to combine metabolic information directly on the corresponding anatomic display $[44,45]$. A study conducted by Scheidler et al. [49] showed a sensitivity and specificity for PCa detection, on a per-sextant basis, of 95 and $91 \%$, respectively, for combined MRSI and MRI, but 61-77 and 46-81\% for MRI alone and 75 and $63 \%$ for MRSI alone. This study demonstrated that the addition of MRSI to MRI significantly improves PCa localization: for locations in the peripheral zone, PPV and NPV were 89-92 and 74-82\%, respectively. Moreover, combined MRI-MRSI seems to be superior to sextant biopsy, with the largest increase in diagnostic accuracy at the apex of the prostate, which is difficult to reach by biopsy [50]. In two recent prospective studies conducted on 39 and 42 patients with elevated PSA levels, that used prostate biopsy as reference standard, it has been reported that combined MRI and MRSI increase the accuracy in PCa detection and localization to 79 and $74.2 \%$, respectively [51, 

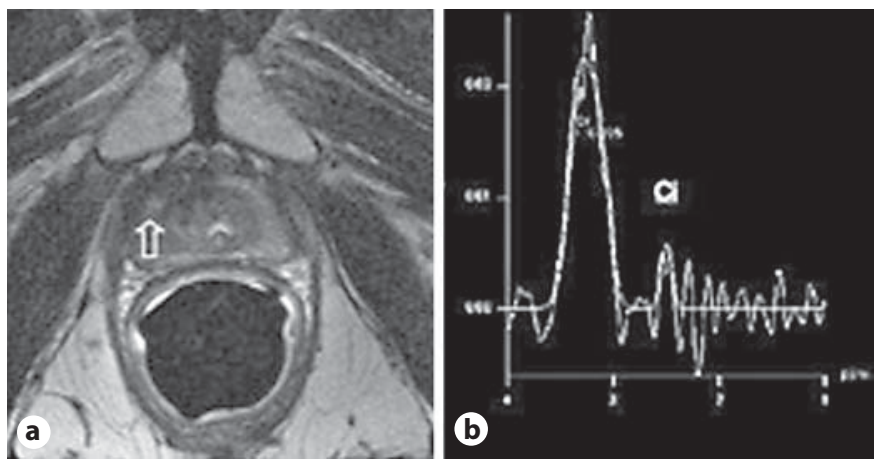

Fig. 4. MRI and MRSI from a patient with PCa. a $T_{2}$-weighted axial image shows a large region of hypointensity in the right midgland (arrow). b Spectrum obtained from the same area demonstrates an elevated ratio of choline $(\mathrm{Cho})$ and creatine $(\mathrm{Cr})$ to citrate $(\mathrm{Ci})$.

52]. However, Prando et al. [53] found that prostate biopsy directed with endorectal MRSI may help to increase the PCa detection rate in patients with an elevated PSA and a previous negative biopsy result.

Limitations of MRSI are: long acquisition time, possible variability in results dependent on post-processing or shimming, no direct visualization of the periprostatic anatomy and therefore expensive procedure. In addition, a previous prostate biopsy may lead to spectral degradation which makes accurate interpretation of the metabolite ratios unreliable, although an MRSI should not be performed within 8 weeks after biopsy [54]. These limitations of MRSI might be improved by new technical developments and the use of higher magnetic fields (3.0 T). Further studies would be desirable to compare US techniques (i.e. high resolution, contrast enhanced, and elastography) with combined MRI/MRSI findings for PCa detection. Moreover, the high specificity of MRSI is of interest to assess low-risk patients who may be candidates for watchful waiting or deferred therapy [55].

\section{Dynamic Contrast Material-Enhanced MRI}

It is well known that the number of vessels increases in cancerous tissue and tumor vessels have a greater permeability [56]. Experimental studies have shown that contrast enhancement parameters, such as mean transit time, blood flow, permeability surface area and interstitial volume, are significantly higher in cancerous tissue than in normal tissue, and therefore allow differentiation between benign and malignant tissue [57-61]. DCE-MRI

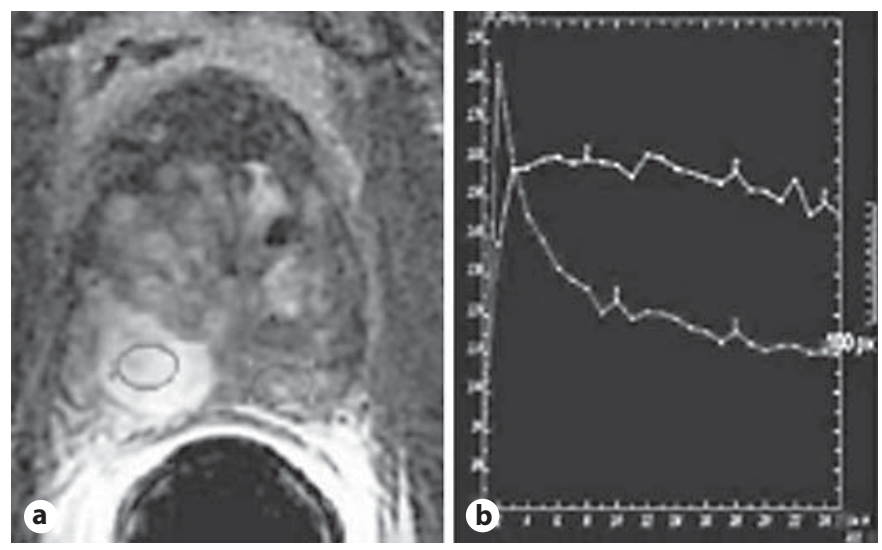

Fig. 5. a DCE-MRI image shows a lesion with early enhancement in the right peripheral zone. b Perfusion graph shows an early enhancement peak, followed by washout in the tumor area and progressive and persistent enhancement of the normal peripheral zone on the left.

is based on repetitive acquisition of sequential images during the passage of a contrast agent within a tissue of interest (fig. 5). Clinical experiences with this technique were first reported in the mid-1990s and, at present, there are only limited data on $\mathrm{T}_{2}$-WI MRI and PCa in the literature. Engelbrecht et al. [62] and Kim et al. [63] showed the usefulness of measurements of relative peak enhancement, and wash-in and wash-out rate for PCa detection and localization. In their study, sensitivity and specificity of peripheral zone cancer detection on parametric images of the wash-in rate were 96 and $97 \%$, respectively, but 75 and $53 \%$ on $\mathrm{T}_{2}$-WI $(\mathrm{p}<0.05)$. However, they also observed significant overlap between the wash-in rate for cancer and that for normal tissue in the transitional zone. Several studies on DCE-MRI that used surgical pathology as the reference standard have reported sensitivity, specificity, and accuracy levels ranging from 69 to $95 \%$, from 80 to $96.2 \%$, and from 77.5 to $92 \%$, respectively [6367]. In a prospective study of 34 patients, with a mean PSA of $8 \mathrm{ng} / \mathrm{ml}$, using whole-mount histopathology section findings as the reference standard, Fütterer et al. [68] found that for the localization of tumors with volumes of $\geq 0.5 \mathrm{~cm}^{3}$, interpretation of $\mathrm{T}_{1}$-WI of DCE-MRI in conjunction with $\mathrm{T}_{2}$-WI of MRI led to an increase in sensitivity from 69 to $95 \%$, specificity from 80 to $96 \%$ and accuracy from 81 to $93 \%$. Moreover, combined DCE-MRI and 3-D MRSI significantly improve the accuracy in $\mathrm{PCa}$ localization, compared with $\mathrm{T}_{2}$-WI MRI alone $(\mathrm{p}<0.01)$ [67]. However, more recently, Jackson et al. [69] reported that DCE-MRI sensitivity was higher than conventional 


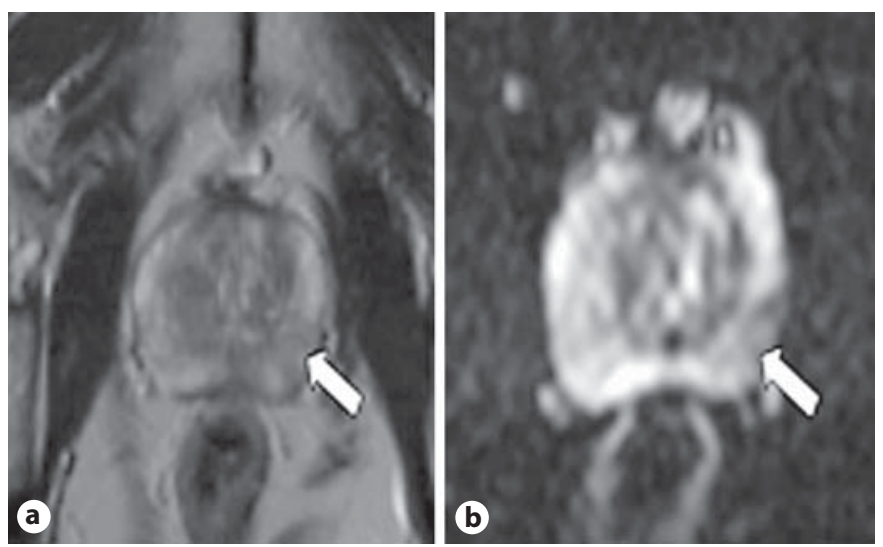

Fig. 6. a $\mathrm{T}_{2}$-weighted axial image shows an area of hypointense signal in the left peripheral zone (arrow). b The corresponding DWI-MRI shows restricted diffusion in the same area, most consistent with PCa. Histopathology showed a tumor with a Gleason score of 7 .

MRI ( $\mathrm{T}_{2}-\mathrm{WI}$ ) for tumor localization (50 vs. $21 \%$; $\mathrm{p}=$ 0.006 ), but specificity was similar ( 85 vs. $81 \%$; $\mathrm{p}=0.593$ ). The superior sensitivity of DCE-MRI compared with $\mathrm{T}_{2^{-}}$ WI, together with its high specificity, is arguably sufficient for its use in guiding radiotherapy boosts in PCa.

Thus, DCE-MRI has the advantage of providing direct depiction of tumor vascularity and may obviate the use of an endorectal coil. Nevertheless, the limitations of this technique include unsatisfactory depiction of transitional zone cancer in patients with hypervascular benign prostatic hyperplasia. In addition, there is as yet no consensus with regard to the best acquisition protocol and the optimal perfusion parameter for differentiating cancer from normal tissue.

\section{Diffusion-Weighted MRI}

The diffusion properties of tissue are related to the amount of interstitial free water and permeability [70]. DW-MRI derives its image contrast from differences in the motion of water molecules between tissues. In general, cancer tends to have more restricted diffusion than normal tissue, because of the higher cell densities and abundance of intra- and intercellular membranes in cancer $[70,71]$. These images can be acquired quickly without the administration of exogenous contrast medium. DW-MRI yields qualitative and quantitative information: qualitative assessment of relative tissue signal attenuation at DW-MRI is used for tumor detection and characterization; quantitative analysis of DW-MRI is achieved by calculation of the apparent diffusion coefficient
(ADC). The ADC is calculated for each pixel of the image and is displayed as a parametric map (ADC map) [72] (fig. 6). A retrospective study comparing MRI alone to combined DW-MRI/MRI in 124 patients with clinically suspected PCa demonstrated that the addition of DW imaging to conventional $\mathrm{T}_{2}$-WI imaging significantly improved tumor detection $(\mathrm{p}=0.0468)$ compared with conventional MRI alone [73]. The sensitivity, specificity, PPV, and NPV of combined DW-MRI/MRI for PCa detection were reported to be $86,84,90$, and $79 \%$, respectively [73]. A recent study [74] showed that ADC values of malignant prostate tissue were significantly lower than in benign tissue. In this study, DW-MRI had a reported sensitivity of $86.7 \%$ and specificity of $72.2 \%$ for PCa detection in the peripheral zone [74], and the water diffusion within prostate tumors was significantly different in patients with low-risk disease than in patients with intermediate or high-risk disease. The authors concluded that DW-MRI can potentially identify poorly differentiated tumors, as these demonstrate earlier and faster enhancement [74]. However, other studies did not confirm these findings [75-78]. DWI has advantages such as short acquisition time and high contrast resolution between tumors and normal tissue. Nevertheless, this technique is limited by poor spatial resolution and the potential risk of image distortion caused by post-biopsy hemorrhage, which results in magnetic field inhomogeneity [70-74].

\section{Role of MRI after Previous Negative Biopsy}

One of the most challenging aspects of PCa diagnosis concerns patients with persistent elevation of serum PSA levels and previous negative TRUS-guided random biopsies of the prostate. It has been recommended that these patients repeat biopsy $[79,80]$. The concept of performing MRI prior to biopsies has been evaluated, and several recent studies focus on this clinical setting [81, 82]. In one study published by Perrotti et al. [83] in 1999, the ability of endorectal MRI to detect PCa foci was examined prospectively in 33 consecutive men with one or more prior negative prostatic biopsies. The areas of interest on endorectal MRI were mapped as low, moderate or high suspicion for carcinoma on a prostate model; directed needle biopsy cores of the prostate were obtained based on this model, and the histopathological findings were compared with MRI results: PPV, NPV and accuracy of endorectal MRI were $40 \%$ (moderate or high suspicion), 94.4\% (low suspicion) and 69.7\%, respectively [83]. On multivariate analysis, positive endorectal MRI was associated with an 11.3-fold risk of positive biopsy [74]. In a prospective study conducted on 44 patients with a PSA 
$>4 \mathrm{ng} / \mathrm{ml}$ or suspicious free-to-total PSA ratios (i.e. $<15 \%$ ) in whom prior TRUS-guided biopsy failed to demonstrate a tumor, Beyersdorff et al. [9] found that MRI had a sensitivity of $83 \%$ and a PPV of $50 \%$ for PCa detection. These values were 33 and $67 \%$ for DRE, and 33 and 57\% for TRUS, respectively [9]. Moreover, in retrospective site-by-site analysis, MRI results did not correlate significantly with individual biopsy site findings $(\mathrm{p}=0.126)$; sensitivity was $65 \%$ and PPV was $12 \%$ [9]. In another study, Comet-Batlle et al. [10] assessed the value of endorectal MRI in the early diagnosis of $\mathrm{PCa}$, and compared this test to PSA and DRE in the prediction of negative biopsies. They concluded that, in patients with elevated PSA and/or abnormal DRE with two previous negative biopsies, MRI is a useful test to rule out PCa when negative, avoiding subsequent biopsies, as they have a low chance of positive biopsy. More recent studies have been conducted to asses the value and the ability of combined conventional/functional MRI to detect PCa foci in men with prior negative TRUS-guided prostate biopsy [11, 8487]. The study by Yuen et al. [11] investigated 24 patients with prior negative TRUS-guided prostate biopsy. Sensitivity, specificity, PPV, NPV, and the accuracy of MRI, MRSI and combined MRI/MRSI for PCa detection were 57.1, 57.1 and $100.0 \%$ (sensitivity), 88.2, 82.4 and 70.6\% (specificity), 66.7, 57.1 and 58.3\% (PPV), 83.3, 82.1 and $100 \%$ (NPV), and 79.2, 75.0 and 79.2\% (accuracy), respectively [11]. Similar results were found by Bhatia et al. [84], in which sensitivity, specificity, PPV, NPV and accuracy of combined MRI/MRSI for detection of PCa were 100, $84,40,100$, and $86 \%$, respectively. More recently, Sciarra et al. [85] prospectively analyzed the role of magnetic MRSI and DCE-MR in the detection of prostate tumor foci in 180 patients with persistently elevated prostatespecific antigen levels (in the range of $\geq 4 \mathrm{ng} / \mathrm{ml}$ to $<10$ $\mathrm{ng} / \mathrm{ml}$ ) and prior negative random biopsy. This study demonstrated that MRSI had $92.3 \%$ sensitivity, $88.2 \%$ specificity, $85.7 \%$ PPV, 93.7\% NPV, and 90\% accuracy; DCE-MRI had $84.6 \%$ sensitivity, $82.3 \%$ specificity, $78.5 \%$ PPV, $87.5 \% \mathrm{NPV}$, and $83.3 \%$ accuracy; the association MRSI plus DCE-MRI had $92.6 \%$ sensitivity, $88.8 \%$ specificity, 88.7\% PPV, 92.7\% NPV, and 90.7\% accuracy, for predicting $\mathrm{PCa}$ detection. In a recent review conducted by Lawrentschuk and Fleshner [86], six studies with a total of 215 patients were examined to assess the efficacy of MRI for targeting cancer when compared to biopsies in patients with previous negative prostate biopsies and persistently elevated PSA levels. The cancer detection rate at re-biopsy was $21-40 \%$. For MRI or combined MRI/MR spectroscopy, the overall sensitivity, specificity and accu- racy for predicting positive biopsies were 57-100, 44-96 and $67-85 \%$, respectively [85]. In five studies, specific MRI-targeted biopsies and standard cores were taken, with a significant proportion $(34 / 63,54 \%)$ having cancer detected purely because of the MRI-targeted cores [85]. A recent study [87] suggested that combined DW-MRI/ MRI on $3 \mathrm{~T}$ has the potential to provide important lesion localization before a repeat biopsy in patients with previous negative random biopsy and persistently elevated PSA levels.

\section{Conclusions}

The degree to which imaging techniques are seen as an indispensable and vital part in diagnostic procedures presents a specific quality feature in urology. To date, considerable advances have been made in organ-confined PCa imaging, particularly in functional MR. The addition of functional $\mathrm{MR}$ techniques to $\mathrm{T}_{2}$-weighted MRI can provide metabolic information, display altered cellularity and aid in noninvasive characterization of tissue and tumor vascularity. This may improve cancer detection, especially in patients with previous negative biopsies. Moreover, functional MRI has still several limitations, mainly the limited availability, the high costs and the lack of standardized imaging parameters. Another important limitation is the wide variability in the specificity and sensitivity values reported in several studies that causes anxiety among patients and unease for the urologist. Furthermore, studies comparing MRI-guided with real-time TRUS-guided biopsy have been performed, and newer ultrasound techniques such as contrast-enhanced US and elastography are available. Prostate MRI is still evolving, and the potential of the technology may improve its utility and efficacy; however, large studies are necessary to verify these preliminary results. One of the difficulties with a rapidly developing technology such as MRI is that as results are published, newer generations of equipment emerge, making the last data appear obsolete. This brings up two unanswered questions: how do we analyze and display this large amount of imaging data, and which kind of lesions are we willing to discover? However, it is important to focus on specific scenarios and critically review publications periodically so that we may pause, reflect on results and then redirect research questions as necessary. The risk of not doing so is that we may never completely define a technology or understand its relevance to current patients, or adequately plan to answer the remaining questions. 


\section{References}

1 Farley J, Parkin DM, Steliarova-Foucher: Estimates of cancer incidence and mortality in Europe in 2008. Eur J Cancer 2010;46:765781.

2 Wolf AM, Wender RC, Etzioni RB, Thompson IM, D’Amico AV, Volk RJ, Brooks DD, Dash C, Guessous I, Andrews K, DeSantis C, Smith RA: American Cancer Society Prostate Cancer Advisory Committee. CA Cancer J Clin 2010;60:70-98.

- 3 Aigner F, Pallwein L, Pelzer A, Schaefer G, Bartsch G, Nedden D, Frauscher F: Value of magnetic imaging in prostate cancer diagnosis. World J Urol 2007;25:351-359.

-4 Norberg M, Egevad L, Holmberg L, Sparen P, Norlen BJ, Busch C: The sextant protocol for ultrasound-guided core biopsies of the prostate underestimates the presence of cancer. Urology 1997;50:562-566.

5 Chen ME, Troncoso P, Johnston DA, Tang K, Babaian RJ: Optimization of prostate biopsy strategy using computer based analysis. J Urol 1997;158:2168-2175.

-6 Keetch DW, Catalona WJ, Smith DS: Serial prostatic biopsies in men with persistently elevated serum prostate specific antigen values. J Urol 1994;151:1571-1574.

-7 Kelloff GJ, Choyke P, Coffey DS, Prostate Cancer Imaging Working Group: Challenges in clinical prostate cancer: role of imaging. AJR 2009;192:1455-1470.

-8 Seitz M, Shukla-Dave A, Bjartell A, Touijer K, Sciarra A, Bastian PJ, Stief C, Hricak H, Graser A: Functional magnetic resonance imaging in prostate cancer. Eur Urol 2009; 55:801-814.

\9 Beyersdorff D, Taupitz M, Winkelmann B, Fischer T, Lenk S, Loening SA, Hamm B: Patients with a history of elevated prostate-specific antigen levels and negative transrectal US-guided quadrant or sextant biopsy results: value of MR imaging. Radiology 2002; 224:701-706.

10 Comet-Batlle J, Vilanova-Busquets JC, Saladié-Roig JM, Gelabert-Mas A, Barceló-Vidal C: The value of endorectal MRI in the early diagnosis of prostate cancer. Eur Urol 2003;44:201-208.

11 Yuen JS, Thng CH, Tan PH, Khin LW, Phee SJ, Xiao D, Lau WK, Ng WS, Cheng CW: Endorectal magnetic resonance imaging and spectroscopy for the detection of tumor foci in men with prior negative transrectal ultrasound prostate biopsy. J Urol 2004; 171:14821486.

12 Amsellem-Ouazana D, Younes P, Conquy S, Peyromaure M, Flam T, Debré B, Zerbib M: Negative prostatic biopsies in patients with a high risk of prostate cancer. Is the combination of endorectal MRI and magnetic resonance spectroscopy imaging (MRSI) a useful tool? A preliminary study. Eur Urol 2005;47: 582-586.
13 Lattouf JB, Grubb RL 3rd, Lee SJ, Bjurlin MA, Albert P, Singh AK, Ocak I, Choyke P, Coleman JA: Magnetic resonance imagingdirected transrectal ultrasonography-guided biopsies in patients at risk of prostate cancer. BJU Int 2007;99:1041-1046.

14 Flanigan RC, Catalona WJ, Richie JP, Ahmann FR, Hudson MA, Scardino PT, deKernion JB, Ratliff TL, Kavoussi LR, Dalkin BL: Accuracy of digital rectal examination and transrectal ultrasonography in localizing prostate cancer: results of a multicenter clinical trial of 6,630 men. J Urol 1994;152: 1506-1509.

15 Eichler K, Hempel S, Wilby J, Myers L, Bachmann LM, Kleijnen J: Diagnostic value of systematic biopsy methods in the investigation of prostate cancer: a systematic review. J Urol 2006; 175:1605-1612.

16 Delongchamps NB, de la Roza G, Jones R, Jumbelic M, Haas GP: Saturation biopsies on autopsied prostates for detecting and characterizing prostate cancer. BJU Int 2009;10: 49-54.

17 Rifkin MD, Dähnert W, Kurtz AB: State of the art: endorectal sonography of prostate gland. AJR Am J Roentgenol 1990;154:691700.

18 Chrouser KL, Lieber MM: Extended and saturation needle biopsy. Curr Urol Rep 2004;5: 226-230.

19 Norberg M, Egevad L, Holmberg L, Sparén P, Norlén BJ, Busch C: The sextant protocol for ultrasound-guided core biopsies of the prostate underestimates the presence of cancer. Urology 1997;50:562-566.

20 Loch T: Computerized supported transrectal ultrasound (CTRUS) in the diagnosis of prostate cancer. Urologe A 2004;43:13771384.

21 Balaji KC, Fair WR, Feleppa EJ, Porter CR, Tsai H, Liu T, Kalisz A, Urban S, Gillespie J: Role of advanced 2 and 3 dimensional ultrasound for detecting prostate cancer. J Urol 2002;168:2422-2425.

$\checkmark 22$ Abul FT, Arun N, Abu-Assi MA, Asbeutah AM: Transrectal ultrasound guided biopsy for detecting prostate cancer: can random biopsies be reduced using the 4-dimensional technique? Int Urol Nephrol 2007;39:517524.

23 Pelzer A, Bektic J, Berger AP, Pallwein L, Halpern EJ, Horninger W, Bartsch G, Frauscher F: Prostate cancer detection in men with prostate specific antigen 4 to $10 \mathrm{ng} /$ $\mathrm{ml}$ using a combined approach of contrast enhanced colour Doppler targeted and systematic biopsy. J Urol 2005;173:1926-1929.

24 Halpern EJ, Ramey JR, Strup SE, Frauscher F, McCue P, Gomella LG: Detection of prostate carcinoma with contrast-enhanced sonography using intermittent harmonic imaging. Cancer 2005;104:2373-2383.
-25 Yi A, Kim JK, Park SH, Kim KW, Kim HS, Kim JH, Eun HW, Cho KS: Contrast-enhanced sonography for prostate cancer detection in patients with indeterminate clinical findings. Am J Roentgenol 2006;186: 1431-1435.

26 Drudi FM, Giovagnorio F, Carbone A, Ricci P, Petta S, Cantisani V, Ferrari FS, Marchetti F, Passariello R: Transrectal colour Doppler contrast sonography in the diagnosis of local recurrence after radical prostatectomy: comparison with MRI. Ultraschall Med 2006;27: 146-151.

-27 Colon PJ 3rd, Richards DR, Moreno CA, Murgo JP, Cheirif J: Benefits of reducing the cardiac cycle-triggering frequency of ultrasound imaging to increase myocardial opacization with FS069 during fundamental and second harmonic imaging. J Am Soc Echocardiogr 1997;10:602-607.

28 Broillet A, Puginier J, Ventrone R, Schneider $\mathrm{M}$ : Assessment of myocardial perfusion by intermittent harmonic power Doppler using SonoVue, a new ultrasound contrast agent. Invest Radiol 1998;33:209.

29 Halpern EJ, Verkh L, Forsberg F, Gomella LG, Mattrey RF, Goldberg BB: Initial clinical experience with contrast-enhanced sonography of the prostate. Am J Roentgenol 2000; 174:1575-1580.

-30 Miyanaga N, Akaza H, Yamakawa M, Oikawa T, Sekido N, Hinotsu S, Kawai K, Shimazui T, Shiina T: Tissue elasticity imaging for diagnosis of prostate cancer: a preliminary report. Int J Urol 2006;13:1514-1518.

- 31 König K, Scheipers U, Pesavento A, Lorenz A, Ermert H, Senge T: Initial experiences with real-time elastography guided biopsies of the prostate. J Urol 2005;174:115-117.

- 32 Pallwein L, Mitterberger M, Struve P, Horninger W, Aigner F, Bartsch G, Gradl J, Schurich M, Pedross F, Frauscher F: Comparison of sonoelastography guided biopsy with systematic biopsy: impact on prostate cancer detection. Eur Radiol 2007; 17:22782285.

33 Singh AK, Kruecker J, Xu S, Glossop N, Guion P, Ullman K, Choyke PL, Wood BJ: Initial clinical experience with real-time transrectal ultrasonography-magnetic resonance imaging fusion-guided prostate biopsy. BJU Int 2007;101:841-845.

- $34 \mathrm{Xu} \mathrm{S,} \mathrm{Kruecker} \mathrm{J,} \mathrm{Turkbey} \mathrm{B,} \mathrm{Glossop} \mathrm{N,}$ Singh AK, Choyke P, Pinto P, Wood BJ: Realtime MRI-TRUS fusion for guidance of targeted prostate biopsies. Comput Aided Surg 2008;13:255-264.

- 35 Puech P, Huglo D, Petyt G, Lemaitre L, Villers A: Imaging of organ-confined prostate cancer: functional ultrasound, MRI and $\mathrm{PET} /$ computed tomography. Curr Opin Urol 2009;19:168-176. 
36 Fütterer JJ, Engelbrecht MR, Jager GJ, Hartman RP, King BF, Hulsbergen-Van de Kaa CA, Witjes JA, Barentsz JO: Prostate cancer: comparison of local staging accuracy of pelvic phased-array coil alone versus integrated endorectal-pelvic phased-array coils: local staging accuracy of prostate cancer using endorectal coil MR imaging. Eur Radiol 2007; 17:1055-1065.

- 37 Beyersdorff D, Winkel A, Hamm B, Lenk S, Loening SA, Taupitz M: MR imaging-guided prostate biopsy with a closed MR unit at 1.5 T: initial results. Radiology 2005;234:576581.

-38 Schnall MD, Pollack HM: Magnetic resonance imaging of the prostate. Urol Radiol 1990;12:109-114.

- 39 Ikonen S, Kivisaari L, Vehmas T, Tervahartiala P, Salo JO, Taari K, Rannikko S: Optimal timing of post-biopsy MR imaging of the prostate. Acta Radiol 2001;42:70-73.

-40 White S, Hricak H, Forstner R, Kurhanewicz J, Vigneron DB, Zaloudek CJ, Weiss JM, Narayan P, Carroll PR: Prostate cancer: effect of postbiopsy haemorrhage on interpretation of MR images. Radiology 1995;195:385-390.

41 Hricak H, White S, Vigneron D, Kurhanewicz J, Kosco A, Levin D, Weiss J, Narayan P, Carroll PR: Carcinoma of the prostate gland: MR imaging with pelvic phased-array coils versus integrated endorectal-pelvic phasedarray coils. Radiology 1994;193:703-709.

-42 Young JC, Jeong K, Namkug K, Kyoung WK, Eugene K: Functiona MR imaging of prostate cancer. Radiographics 2007;27:63-77.

43 Kurhanewicz J, Vigneron D, Carroll P, Coakley F: Multiparametric magnetic resonance imaging in prostate cancer: present and future. Curr Opin Urol 2008; 18:71-77.

44 Chen ME, Troncoso P, Johnston DA, Tang K, Babaian RJ: Functional MR imaging of prostate cancer. Radiographics 2007;27:63-75

45 Claus FG, Hricak H, Hattery RR: Pretreatment evaluation of prostate cancer: role of MR imaging and $1 \mathrm{H}$ MR spectroscopy. Radiographics 2004;24:S167-S180.

- 46 Jung JA, Coakley FV, Vigneron DB, Swanson MG, Qayyum A, Weinberg V, Jones KD, Carroll PR, Kurhanewicz J: Prostate depiction at endorectal MR spectroscopic imaging: investigation of a standardized evaluation system. Radiology 2004;233:701-708.

-47 Shukla-Dave A, Hricak H, Moskowitz C, Ishill N, Akin O, Kuroiwa K, Spector J, Kumar M, Reuter VE, Koutcher JA, Zakian KL: Detection of prostate cancer with MR spectroscopic imaging: an expanded paradigm incorporating polyamines. Radiology 2007; 245:499-506.

-48 Nakashima J, Tanimoto A, Imai Y, Mukai M, Horiguchi Y, Nakagawa K, Oya M, Ohigashi T, Marumo K, Murai M: Endorectal MRI for prediction of tumor site, tumor size, and local extension of prostate cancer. Urology 2004;64:101-105
49 Scheidler J, Hricak H, Vigneron DB, Yu KK, Sokolov DL, Huang LR, Zaloudek CJ, Nelson SJ, Carroll PR, Kurhanewicz J: Prostate cancer: localization with three-dimensional proton MR spectroscopic imaging - clinicopathologic study. Radiology 1999;213:473480.

50 Wefer AE, Hricak H, Vigneron DB, Coakley FV, Lu Y, Wefer J, Mueller-Lisse U, Carroll PR, Kurhanewicz J: Sextant localization of prostate cancer: comparison of sextant biopsy, magnetic resonance imaging and magnetic resonance spectroscopic imaging with step section histology. J Urol 2000;164:400404.

51 Manenti G, Squillaci E, Carlani M, Mancino S, Di Roma M, Simonetti G: Magnetic resonance imaging of the prostate with spectroscopic imaging using a surface coil. Initial clinical experience. Radiol Med (Torino) 2006;111:22-32.

52 Reinsberg SA, Payne GS, Riches SF, Ashley S, Brewster JM, Morgan VA, deSouza NM: Combined use of diffusion-weighted MRI and $1 \mathrm{H}$ MR spectroscopy to increase accuracy in prostate cancer detection. AJR Am J Roentgenol 2007;188:91-98, 153-159.

53 Prando A, Kurhanewicz J, Borges AP, Oliveira EM Jr, Figueiredo E: Prostatic biopsy directed with endorectal MR spectroscopic imaging findings in patients with elevated prostate specific antigen levels and prior negative biopsy findings: early experience. Radiology 2005;236:903-910.

-54 Coakley FV, Kurhanewicz J, Lu Y, Jones KD, Swanson MG, Chang SD, Carroll PR, Hricak $\mathrm{H}$ : Prostate cancer tumor volume: measurement with endorectal MR and MR spectroscopic imaging. Radiology 2002;223:91-97.

55 Shukla-Dave A, Hricak H, Kattan MW, Pucar D, Kuroiwa K, Chen HN, Spector J, Koutcher JA, Zakian KL, Scardino PT: The utility of magnetic resonance imaging and spectroscopy for predicting insignificant prostate cancer: an initial analysis. BJU Int 2007;99:786-793.

56 Choyke PL: Contrast agents for imaging tumour angiogenesis: is bigger better? Radiology 2005;235:1-2.

57 Buckley DL, Roberts C, Parker GJ, Logue JP, Hutchinson CE: Prostate cancer: evaluation of vascular characteristics with dynamic contrast enhanced T1-weighted MR imaging - initial experience. Radiology 2004; 233:709-715

58 Brix G, Semmler W, Port R, Schad LR, Layer G, Lorenz WJ: Pharmacokinetic parameters in CNS Gd-DTPA enhanced MRI. J Comput Assist Tomogr 1991;15:621-628.

59 Hoffmann U, Brix G, Knopp MV, Hess T, Lorenz WJ: Pharmacokinetic mapping of the breast: a new method for dynamic MRmammography. Magn Reson Med 1995;33: 506-514.
60 Hawighorst H, Knopp MV, Debus J, Hoffmann U, Grandy M, Griebel J, Zuna I, Essig M, Schoenberg SO, DeVries A, Brix G, van Kaick G: Pharmacokinetic MRI for assessment of malignant glioma response to stereotactic radiotherapy: initial results. J Magn Reson Imaging 1998;8:783-788.

61 Port RE, Knopp MV, Hoffmann U, MilkerZabel S, Brix G: Multicompartment analysis of gadolinium chelate kinetics: blood-tissue exchange in mammary tumors as monitored by dynamic MR imaging. J Magn Reson Imaging 1999;10:233-241.

62 Engelbrecht MR, Huisman HJ, Laheij RJ, Jager GJ, van Leenders GJ, Hulsbergen-Van De Kaa CA, de la Rosette JJ, Blickman JG, Barentsz JO: Discrimination of prostate cancer from normal peripheral zone and central gland tissue by using dynamic contrast-enhanced MR imaging. Radiology 2003;229: 248-254

63 Kim JK, Hong SS, Choi YJ, Park SH, Ahn H, Kim CS, Cho KS: Wash-in rate on the basis of dynamic contrast-enhanced MRI: usefulness for prostate cancer detection and localization. J Magn Reson Imaging 2005;22:639646.

64 Jager GJ, Ruijter ET, van de Kaa CA, de la Rosette JJ, Oosterhof GO, Thornbury JR, Ruijs SH, Barentsz JO: Dynamic TurboFLASH subtraction technique for contrastenhanced MR imaging of the prostate: correlation with histopathologic results. Radiology 1997;203:645-652.

65 Ogura K, Maekawa S, Okubo K, Aoki Y, Okada T, Oda K, Watanabe Y, Tsukayama C, Arai $\mathrm{Y}$ : Dynamic endorectal magnetic resonance imaging for local staging and detection of neurovascular bundle involvement of prostate cancer: correlation with histopathologic results. Urology 2001;57:721-726.

66 Kiessling F, Lichy M, Grobholz R, Heilmann M, Farhan N, Michel MS, Trojan L, Ederle J, Abel U, Kauczor HU, Semmler W, Delorme S: Simple models improve the discrimination of prostate cancers from the peripheral gland by T1-weighted dynamic MRI. Eur Radiol 2004; 14:1793-1801.

67 Schlemmer HP: Negative prostatic biopsies in patients with a high risk of prostate cancer. Is the combination of endorectal MRI and magnetic resonance spectroscopy imaging (MRSI) a useful tool? A preliminary study. Eur Urol 2005;47:582-586.

68 Fütterer JJ, Heijmink SW, Scheenen TW, Veltman J, Huisman HJ, Vos P, HulsbergenVan de Kaa CA, Witjes JA, Krabbe PF, Heerschap A, Barentsz JO: Prostate cancer localization with dynamic contrast-enhanced MR imaging and proton MR spectroscopic imaging. Radiology 2006;241:449-458.

- 69 Jackson ASN, Reinsberg SA, Sohaib SA, Charles-Edwards M: Dynamic contrast-enhanced MRI for prostate cancer localization. Br J Rad 2002;82:148-156. 
>70 Tien RD, Felsberg GJ, Friedman H, Brown M, MacFall J: MR imaging of high-grade cerebral gliomas: value of diffusion-weighted echoplanar pulse sequences. AJR Am J Roentgenol 1994;162:671-677.

-71 Eis M, Els T, Hoehn-Berlage M: High resolution quantitative relaxation and diffusion MRI of three different experimental tumors in rat. Magn Reson Med 1995;34:835-844.

72 Koh DM, Collins DJ: Diffusion-weighted MRI in the body: applications and challenges in oncology. AJR Am J Roentgenol 2007; 188:1622-1635.

73 Shimofusa R, Fujimoto H, Akamata H: Diffusion-weighted imaging of prostate cancer. J Comput Assist Tomogr 2005;29:149-153.

-74 DeSesouza NM, Reinsberg SA, Scurr ED, Brewster JM, Payne GS: Magnetic resonance imaging in prostate cancer: the value of apparent diffusion coefficients for identifying malignant nodules. Br J Radiol 2007;80:9095.

75 Padhani AR: Dynamic contrast-enhanced MRI in clinical oncology: current status and future directions. J Magn Reson Imaging 2002; 16:407-422.

76 Engelbrecht MR, Huisman HJ, Laheij RJ Discrimination of prostate cancer from normal peripheral zone and central gland tissue by using dynamic contrast-enhanced MR imaging. Radiology 2003;229:248-254.
77 Padhani AR, Gapinski CJ, Macvicar DA: Dynamic contrast enhanced MRI of prostate cancer: correlation with morphology and tumour stage, histological grade and PSA. Clin Radiol 2000;55:99-109.

78 Alonzi R, Padhani AR, Allen C: Dynamic contrast enhanced MRI in prostate cancer. Eur J Radiol 2007;63:335-350.

79 Yuen JS, Thng CH, Tan PH, Khin LW, Phee SJ, Xiao D, Lau WK, Ng WS, Cheng CW: Endorectal magnetic resonance imaging and spectroscopy for the detection of tumor foci in men with prior negative transrectal ultrasound prostate biopsy. J Urol 2004;171:14821486.

80 Ellis WJ, Brawer MK: Repeat prostate needle biopsy: who needs it? J Urol 1995;153:14961498.

81 Villers A, Puech P, Leroy X, et al: Dynamic contrast-enhanced MRI for preoperative identification of localised prostate cancer. Eur Urol Suppl 2007;6:525-532.

82 Kirkham AP, Emberton M, Allen C: How good is MRI at detecting and characterising cancer within the prostate? Eur Urol 2006; 50:1163-1175.

83 Perrotti M, Han KR, Epstein RE, et al: Prospective evaluation of endorectal magnetic resonance imaging to detect tumor foci in men with prior negative prostatic biopsy: a pilot study. J Urol 1999;162:1314-1317.
84 Bhatia C, Phongkitkarun S, Booranapitaksonti D, Kochakarn W, Chaleumsanyakorn P: Diagnostic accuracy of MRI/MRSI for patients with persistently high PSA levels and negative TRUS-guided biopsy results. J Med Assoc Thai 2007;90:1391-1399.

85 Sciarra A, Panebianco V, Ciccariello M, Salciccia S, Cattarino S, Lisi D, Gentilucci A, Alfarone A, Bernardo S, Passariello R, Gentile V: Value of magnetic resonance spectroscopy imaging and dynamic contrast-enhanced imaging for detecting prostate cancer foci in men with prior negative biopsy. Clin Cancer Res 2010;16:1875-1883.

-86 Lawrentschuk N, Fleshner N: The role of magnetic resonance imaging in targeting prostate cancer in patients with previous negative biopsies and elevated prostate-specific antigen levels. BJU Int 2009;103:730733.

87 Park BK, Lee HM, Kim CK, Choi HY, Park JW: Lesion localization in patients with previous negative transrectal ultrasound biopsy and persistently elevated prostate specific antigen levels using diffusion-weighted imaging at three Tesla before rebiopsy. Invest Radiol 2008;43:789-793. 